\title{
Comparison among High-Frequency and Line-Frequency Commutated Rectifiers Complying with IEC 61000-3-2 Standards
}

\author{
José Antenor Pomilio \\ School of Electrical and Computer Engineering, University of Campinas \\ C. P. 6101 13081-970 Campinas - BRAZIL \\ Tel. (+55.19) 7883748 - Fax (+55.19) 2891395 \\ e-mail: antenor@dsce.fee.unicamp.br \\ Giorgio Spiazzi, Simone Buso \\ Department of Electronics and Informatics, University of Padova \\ Via Gradenigo 6A - 35131 Padova - ITALY \\ Tel. (+39.049) 827-7503/7525 - Fax (+39.049) 827-7699/7599 \\ e-mail: giorgio.spiazzi@dei.unipd.it - simone.buso@dei.unipd.it
}

\begin{abstract}
High power factor rectifiers, complying with IEC 61000-3-2 standards have been deeply studied. Two main approaches are usually used: high frequency control of the input current (as in PFCs) and line-frequency commutated rectifiers. The latter represent an interesting solution for large volume applications which do not need a precise output voltage regulation. They provide compliance with a smaller overall reactive component volume as compared to conventional rectifiers with passive L-C filter. Moreover, being the switch turned on and off only twice per line period, the associated losses are very small and the di/dt and dv/dt can be lowered compared to high-frequency commutated rectifiers, thus reducing the high-frequency noise emission and EMI filter requirements. This paper reviews the operating principles of some line-frequency commutated rectifier topologies highlighting their merits and limitations. A comparison among low and high frequency high power factor rectifiers, in terms of circuit complexity, overall reactive component size and performance, is made, thus allowing selection of the most convenient topology for a given application.
\end{abstract}

\section{INTRODUCTION}

High quality rectifiers (also called Power Factor Correctors - PFCs) are rapidly substituting conventional frontend rectifiers due to the low-frequency harmonic limits imposed by international standards like IEC-61000-3-2 [1]. Such high-frequency commutated rectifiers provide very high power factors (actually much higher than what is required by the standards) and a good output voltage regulation, at the expense of an increase of the overall ac-to-dc converter size and cost. The PFC based on the boost converter (HF - boost PFC) operating in the continuous conduction mode (CCM) is the preferred choice, especially in the medium power range.

Nevertheless, some large volume applications still use standard low-cost, high-reliability rectifiers with passive filters in order to improve the quality of the current drawn from the line, even if the volume of the reactive components needed rapidly becomes prohibitive as the power increases [2].

Recently, different line-frequency commutated rectifier topologies were proposed as a trade-off between high-frequency PFCs and completely passive solutions [3-7]. Compliance with IEC-61000-3-2 can be achieved with a reduced overall reactive component size compared to passive solutions. All of them utilise a switch which is turned on and off only twice per line period, thus drastically reducing both conduction and switching losses. Moreover, the limited di/dt and dv/dt during the commutations allow reduction (or even elimination) of the high-frequency noise emission and of the EMI filter requirements.

In this paper, some of these different line-frequency commutated rectifier topologies are reviewed with the aim of providing the tools for the best choice for a given application. A comparison with a boost-type high-frequency commutated PFC is made, observing aspects as: input current distortion and output voltage regulation, circuit complexity, switch current and voltage stresses, reactive component size, etc. Such evaluation is carried out for different power levels, ranging from $300 \mathrm{~W}$ up to $1.2 \mathrm{~kW}$.

\section{LINE-FREQUENCY COMMUTATED RECTIFIER TOPOLOGIES}

The schemes of the line-frequency commutated rectifier topologies that are taken into consideration are shown in Fig.1. Each of them contains a line frequency smoothing inductance, L, and an output filter capacitor, C, plus an auxiliary switching unit. Such unit consists of a line-frequency commutated switch, $\mathrm{S}$, plus a diode, D. Topology $\mathrm{T} 2$ also uses an auxiliary capacitor, $\mathrm{C}_{\mathrm{a}}$, and an auxiliary inductance, $\mathrm{L}_{\mathrm{a}}$. Except for diode $\mathrm{D}$, the auxiliary elements are all rated at a small fraction of the output power. Topology $\mathrm{T} 1$ is electrically identical to the HF - boost PFC.

These rectifiers allow compliance with low-frequency harmonic standards, with a reduced smoothing inductor value as compared to passive L-C filters. The principles of operation are now briefly reviewed. 
1) Low-frequency boost PFC (Topology T1): this circuit is topologically identical to a conventional boost PFC, but it operates at low switching frequency: when the switch is turned on the input current starts to increase earlier with respect to the natural diode bridge turn-on instant. During this interval, the input inductor voltage is $\mathrm{u}_{\mathrm{g}}$. When the switch is turned off, the conventional resonance between $\mathrm{L}$ and $\mathrm{C}$ occurs until the input current zeroes, remaining zero until the subsequent line half period. The typical line current is shown in Fig. 2. In the same figure is reproduced the current envelope used in IEC61000-3-2 to define a class D piece of equipment.

2) Modified LF - boost PFC (Topology T2): this converter operates in a slightly different way. Switch $\mathrm{S}$ is turned on around the input voltage zero crossing in an interval in which the input current normally would be zero. This causes a partial discharge of the auxiliary capacitor $\mathrm{C}_{\mathrm{a}}$ through $\mathrm{L}_{\mathrm{a}}$. When the switch is turned off this discharge phase continues through $\mathrm{D}_{\mathrm{a}}$ until the auxiliary inductance current goes to zero. At the end of this interval, capacitor $\mathrm{C}_{\mathrm{a}}$ is charged at a fraction of the output voltage thus causing a premature diode bridge turn-on. The input current increases in a resonant way charging $\mathrm{C}_{\mathrm{a}}$ until diode $\mathrm{D}$ turns on. After that, inductor $\mathrm{L}$ resonates with the output capacitor until the input current zeroes. The typical line current is shown in Fig. 2.

\section{COMPARISON AMONG THE TOPOLOGIES}

\section{A. Compliance with low-frequency harmonic standards.}

For the high-frequency solution, considering operation in

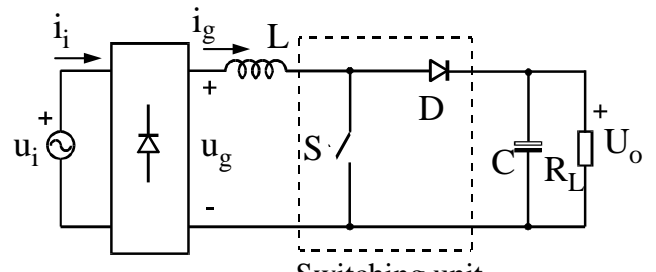

a)

Switching unit

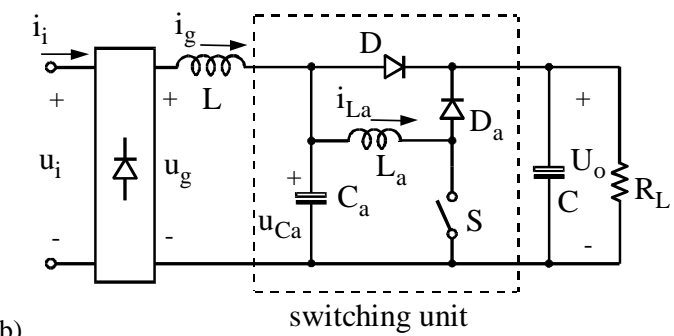

b) switching unit

Fig. 1 - High power factor rectifier topologies: a) low-frequency boost converter T1; b) modified LF-boost converter T2.

the continuous conduction mode and average current control, the current waveform reproduces the voltage shape and the current distortion is practically the same one present in the grid voltage. In the discontinuous conduction mode (DCM), the filtered line current presents higher distortion [8], but usually much lower than the standard limits, as illustrated in Fig. 3.

As far as the input current harmonic content is concerned, the design criteria for the rectifiers shown in Fig. 1 change as a function of the rated power. For a power range below $600 \mathrm{~W}$, the basic idea is to exploit the difference between the absolute harmonic limitations applied to class A loads and the relative limitations applied to class D loads [1]. As known, the difference can be remarkable especially for low power applications. Thus, the goal of these modified rectifiers is to change the shape of the input current so as to stay outside the Class D template, as shown in Fig. 2, for at least 5\% of the line half period.

If the required output power is higher than $600 \mathrm{~W}$, the load is considered in class A, no matter the current waveform. The converters have no longer the aim of modifying the input current to stay out of the class D template, but simply to reduce the current harmonic distortion. In particular, reduction of the third harmonic is accomplished at the expense of an increase of the higher order harmonics. This effect can be seen in Fig. 4 which reports a comparison between the input current spectrum of the passive L-C rectifier and of the topology $\mathrm{T} 1$.

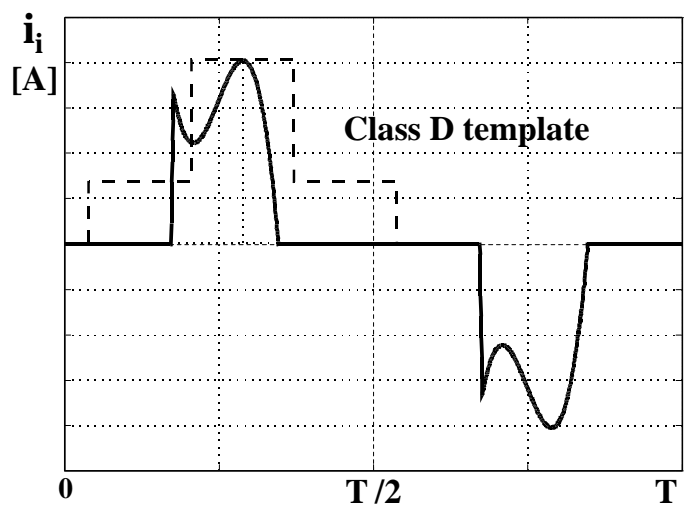

a)

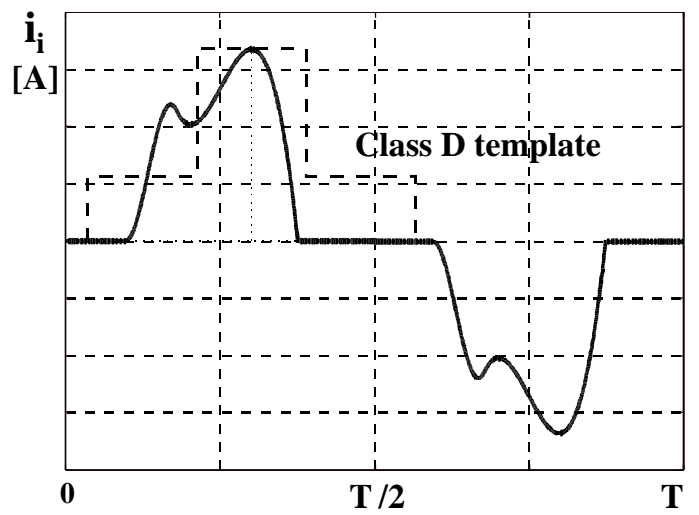

b)

Fig. 2 - Typical input waveforms of the line-frequency commutated rectifiers: a) $\mathrm{T} 1$; b) $\mathrm{T} 2$. 


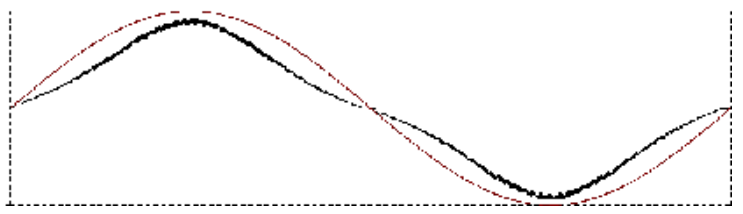

Fig. 3 - Typical line current for HF-boost PFC in DCM.

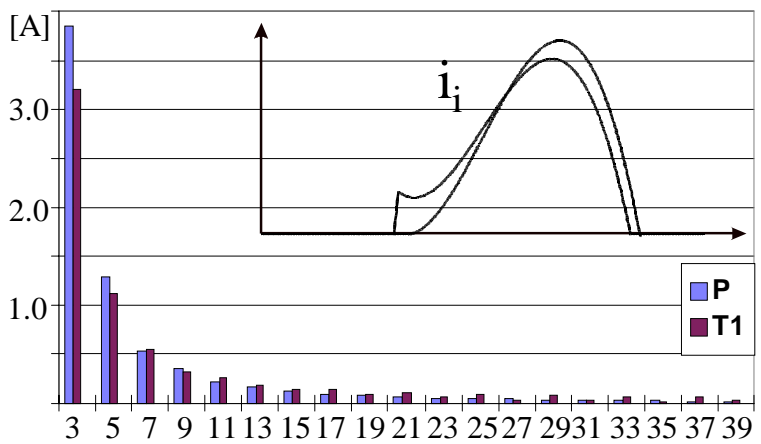

Harmonic order

Fig. 4 - Comparison between the passive L-C rectifier $(\mathrm{P})$ and the LF -boost converter (T1).

Table I and II show comparisons among the topologies, including the rectifier with passive single-cell LC filter. All values are calculated for a $230 \mathrm{~V}_{\mathrm{RMS}}$ input voltage.

The inductance values are the minimum that allow accordance with the standard and were obtained by numerical calculations. The HF-boost inductance value is calculated considering an high-frequency current ripple of $2.6 \mathrm{~A}$ (peak-topeak), a $70 \mathrm{kHz}$ switching frequency and $\mathrm{U}_{\mathrm{o}}=380 \mathrm{~V}$.

\section{B. Output voltage regulation}

For the $\mathrm{HF}$ - boost PFC, an excellent output voltage regulation is obtained along all the load variation range also rejecting input voltage deviations.

The passive solution does not provide any voltage regulation and, due to the voltage drop across the inductance, the output voltage is significantly lower than the peak input voltage.

A certain amount of boost effect is present in the lowfrequency topologies where the energy processed during the switch on interval is transferred to the output capacitance, partially compensating for the input inductance voltage drop.

The effectiveness of this compensation depends on the maximum allowed switch on time which, as discussed in the next item, is limited to keep the switch current stress at an acceptable level. As a consequence, only a limited output voltage regulation can be achieved. In particular, the inductance voltage drop compensation turns out to be more difficult for topology $\mathrm{T} 1$, which requires a bigger inductor. Topology $\mathrm{T} 2$ instead, using a smaller input inductor, can achieve a better or even complete compensation.

Anyway, as the current load is reduced, the on time decreases in order to maintain the output voltage. For a minimum load power $t_{\text {on }}$ goes to zero and the converter operates as a rectifier with passive $\mathrm{L}-\mathrm{C}$ (without the switching unit). Below this power level no output voltage regulation is possible.

Practically no regulation is possible against input voltage deviations, due to the limited switch on time. This consideration is valid for both LF circuits.

\section{Current and voltage stresses}

For the low-frequency topologies, the switch current stress is directly related to the switch on time. The latter should be kept as small as possible in order to maintain the size of the auxiliary magnetic component at a reasonable level (see item E: Inductor size).

Topology T2 has a higher current stress due to the auxiliary capacitor discharge through the small auxiliary inductance. Fig. 5 shows voltage and current waveforms in the auxiliary circuit. Besides the transistor and diode, also the auxiliary capacitor is subjected to an important current stress, indicating the use of a capacitor with small series equivalent resistance $\left(\mathrm{R}_{\mathrm{se}}\right)$.

The current stress in the HF - boost PFC, operating in the CCM, equals the inductor current peak value. The voltage stress is equal to the output voltage for all the three topologies, but usually is higher for the HF - boost, because in this circuit the output voltage is higher than the input peak voltage.

\section{Power Factor}

Considering the current waveforms shown in Fig. 2 it is possible to determine their respective total harmonic distortion (THD), the displacement factor $\left(\cos \phi_{1}\right)$ and the resulting power factor $(\mathrm{PF})$.

Obviously the results for the HF solution are the best, while the topology with passive filter is the worst. Among the active low-frequency circuits, the results for T2 are better than those for T1. This can be explained considering that T2 presents lower peak and RMS values of the input current, thus reducing the THD and improving the power factor.

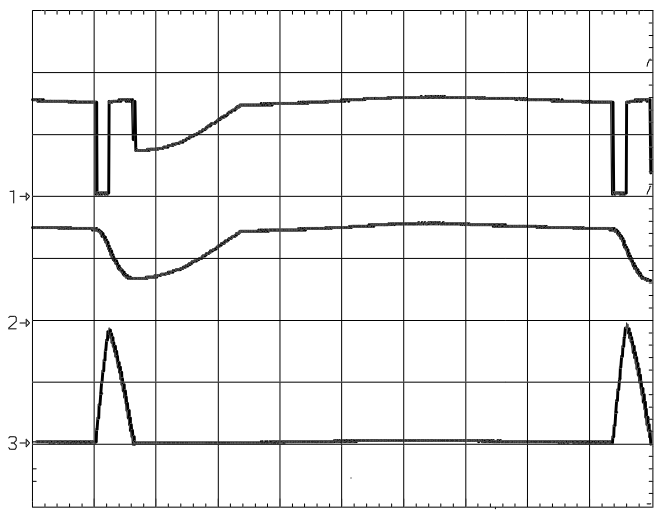

Fig. 5 - Auxiliary circuit waveforms for topology T2: Top: Switch Voltage (200 V/div.)

Middle: Auxiliary capacitor voltage $\left\{\mathrm{u}_{\mathrm{Ca}}\right\}(200 \mathrm{~V} /$ div. $)$ Bottom: Auxiliary inductor current $\left\{\mathrm{i}_{\mathrm{La}}\right\}(20 \mathrm{~A} / \mathrm{div}$. Horiz.: $1 \mathrm{~ms} / \mathrm{div}$. 


\section{E. Inductor size}

As an estimation of the magnetic elements size the product $\mathrm{A}_{\mathrm{e}} \mathrm{A}_{\mathrm{w}}$ (Core transversal area $\mathrm{x}$ Winding window area) can be used. Table II shows the final volume of the inductors, calculated using the values shown below.

For the low frequency converters a FeSi core is considered $\left(\mathrm{B}_{\max } \sim 1.5 \mathrm{~T}\right.$, current density $\mathrm{J}=5 \mathrm{~A} / \mathrm{mm}^{2}$, filling coefficient $\left.\mathrm{k}_{\mathrm{R}}=0.4\right)$. For the $\mathrm{HF}$ - boost, Kool-M $\mu^{\odot}$ (Magnetics) cores were used for $300 \mathrm{~W}$ (77548-A7) and $600 \mathrm{~W}$ (77324-A7) design (expected $\mathrm{B}_{\max } \sim 0.4 \mathrm{~T}$ and $0.7 \mathrm{~T}$ respectively) while a ferrite core (T157-08 Micrometals) is taken into account for the $900 \mathrm{~W}$ and $1200 \mathrm{~W}$ design (expected $\mathrm{B}_{\max } \sim 0.3 \mathrm{~T}$ and $0.4 \mathrm{~T}$ respectively). An inductor temperature elevation of about $40{ }^{\circ} \mathrm{C}$ was considered.

As expected, the high frequency inductor turns out to have smaller size and the difference between low and high frequency solutions becomes more significant as the power increases. Among the LF circuits, topology T2 turns out to need the smaller inductance, even considering the necessity of the auxiliary inductor.

\section{F. Losses}

The power losses associated with the magnetic components and input rectifier were calculated for all topologies and power range. A $1 \mathrm{~V}$ drop per diode was supposed and the power losses parameters associated with the magnetic core materials were taken from the manufacturers' data sheets for the HF solution. For the LF solutions a $3 \mathrm{~W} / \mathrm{kg}$ power loss density was assumed.

TABLE I. COMPARISON AMONG PASSIVE AND ACTIVE RECTIFIERS AT DIFFERENT POWER LEVELS: VOLTAGE AND CURRENT STRESS AND POWER FACTOR

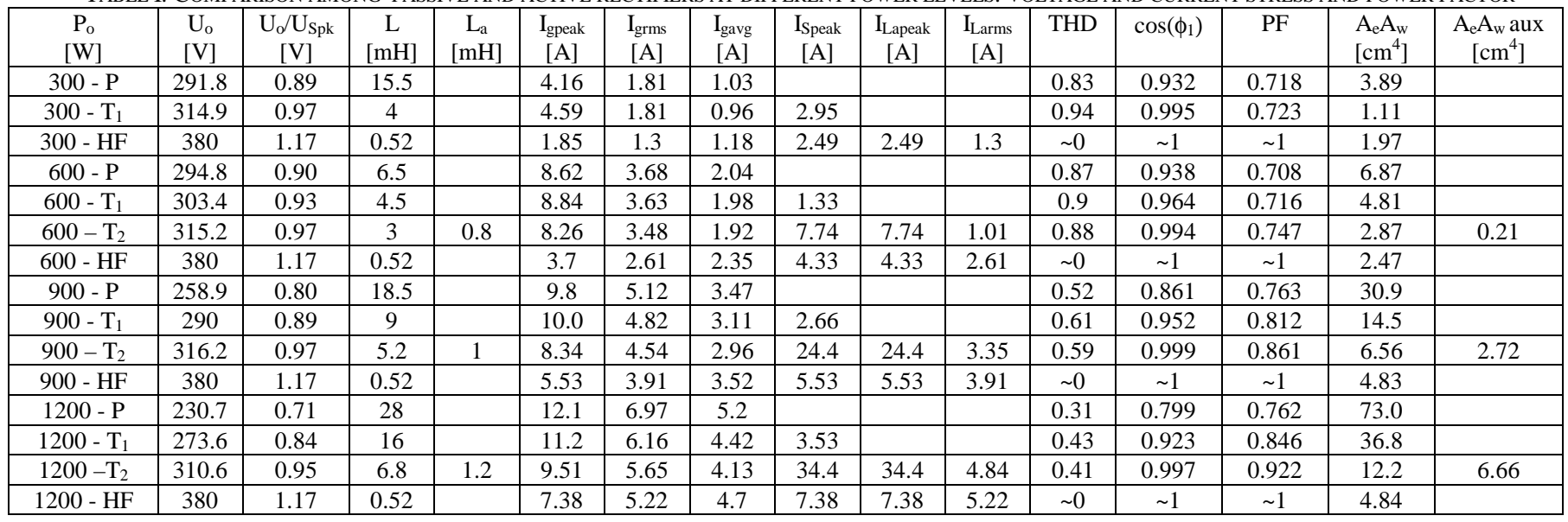

$\mathrm{P}=$ passive $; \mathrm{T}_{1}=\mathrm{LF}-$ boost $\mathrm{T}_{2}=$ modified LF - boost, $\mathrm{HF}-$ boost PFC.

TABLE II. COMPARISON AMONG PASSIVE AND ACTIVE RECTIFIERS AT DIFFERENT POWER LEVELS: VOLUME AND POWER LOSSES

\begin{tabular}{|c|c|c|c|c|c|c|c|c|c|c|c|}
\hline $\begin{array}{c}\mathrm{P}_{\mathrm{o}} \\
{[\mathrm{W}]}\end{array}$ & $\begin{array}{c}\mathrm{V}_{\mathrm{ext}} \\
{\left[\mathrm{cm}^{3}\right]}\end{array}$ & $\begin{array}{c}\mathrm{V}_{\mathrm{Fe}} \\
{\left[\mathrm{cm}^{3}\right]}\end{array}$ & $\begin{array}{c}\mathrm{V}_{\text {ext }} \\
\text { aux } \\
{\left[\mathrm{cm}^{3}\right]}\end{array}$ & $\begin{array}{c}\mathrm{V}_{\mathrm{fe}} \\
\text { aux } \\
{\left[\mathrm{cm}^{3}\right]}\end{array}$ & $\begin{array}{c}\mathrm{P}_{\mathrm{Cu}}{ }^{*} \\
{[\mathrm{~W}]}\end{array}$ & $\begin{array}{c}\mathrm{P}_{\mathrm{Fe}}{ }^{*} \\
{[\mathrm{~W}]}\end{array}$ & $\begin{array}{c}\mathrm{P}_{\text {rect }} \\
{[\mathrm{W}]}\end{array}$ & $\begin{array}{c}\mathrm{P}_{\text {switch }}{ }^{* *} \\
{[\mathrm{~W}]}\end{array}$ & $\begin{array}{c}\mathrm{P}_{\text {cap }} \\
{[\mathrm{W}]}\end{array}$ & $\begin{array}{c}\text { Heatsink } \\
\text { Area } \\
{\left[\mathrm{cm}^{2}\right]}\end{array}$ & $\begin{array}{c}\text { EMI filter } \\
\text { volume } \\
{\left[\mathrm{cm}^{3}\right]}\end{array}$ \\
\hline $300-\mathrm{P}$ & 30.7 & 24.6 & & & 2.98 & 0.58 & 2.06 & & & \\
\hline $300-\mathrm{T}_{1}$ & 11.5 & 9.2 & & & 1.24 & 0.22 & 1.92 & 0.97 & & 5 & \\
\hline $300-\mathrm{HF}$ & 6.84 & & & & 5.3 & 0.73 & 2.36 & 8.9 & & 64 & 131 \\
\hline $600-\mathrm{P}$ & 48 & 38.4 & & & 4.08 & 0.91 & 4.08 & & & & \\
\hline $600-\mathrm{T}_{1}$ & 38.4 & 30.7 & & & 3.22 & 0.73 & 3.96 & 1.98 & & 11 & \\
\hline $600-\mathrm{T}_{2}$ & 26.1 & 21.5 & 3.58 & 2.82 & 2.59 & 0.58 & 3.84 & 1.94 & 0.92 & 11 & \\
\hline $600-\mathrm{HF}$ & 6.84 & & & & 5.3 & 1.47 & 4.70 & 20.5 & & 149 & 131 \\
\hline $900-\mathrm{P}$ & 141 & 112 & & & 13.6 & 2.67 & 6.94 & & & & \\
\hline $900-\mathrm{T}_{1}$ & 90 & 72 & & & 7.04 & 1.71 & 6.11 & 3.14 & & 17.6 & \\
\hline $900-\mathrm{T}_{2}$ & 48 & 38.4 & 26.1 & 21.5 & 6.01 & 1.42 & 5.92 & 3.18 & 7.76 & 17.9 & \\
\hline $900-\mathrm{HF}$ & 10.5 & & & & 3.35 & 2.84 & 7.04 & 31.8 & & 282 & 194 \\
\hline $1200-\mathrm{P}$ & 262 & 206 & & & 25.8 & 4.88 & 10.4 & & & & \\
\hline $1200-\mathrm{T}_{1}$ & 164 & 131 & & & 14.8 & 3.11 & 8.84 & 4.5 & & 25.6 & \\
\hline $1200-\mathrm{T}_{2}$ & 75 & 60 & 48 & 38.4 & 10.5 & 2.33 & 8.26 & 4.64 & 15.2 & 26.3 & \\
\hline $1200-\mathrm{HF}$ & 21.3 & & & & 3.76 & 2.81 & 9.40 & 43.6 & & 495 & 194 \\
\hline
\end{tabular}

* Includes the auxiliary inductor for T2 ** Includes the transistor and the diodes

$\mathrm{P}_{\mathrm{o}}$ : output power; $\mathrm{U}_{\mathrm{o}}$ : output voltage; $\mathrm{U}_{\mathrm{Sp}}$ : input voltage peak value; $\mathrm{I}_{\mathrm{g}}$ : line current; $\mathrm{I}_{\mathrm{S}}$ : switch current; $\mathrm{I}_{\mathrm{La}}$ : auxiliary inductor current; $\mathrm{V}_{\text {ext }}$ : external volume of the inductor (winding volume not included); $\mathrm{V}_{\mathrm{Fe}}$ : magnetic core volume; P: power loss in wiring $\left(\mathrm{P}_{\mathrm{Cu}}\right)$, core $\left(\mathrm{P}_{\mathrm{Fe}}\right)$, input rectifier $\left(\mathrm{P}_{\mathrm{rect}}\right)$, switch and auxiliary diode $\left(\mathrm{P}_{\text {switch }}\right)$ and auxiliary capacitor $\left(\mathrm{P}_{\text {cap }}\right)$ 
The resulting values are not very different. The exception is represented by the wiring losses in the LF circuits that are much higher than in the HF. The reason is that the same current density for all inductor designs $\left(5 \mathrm{~A} / \mathrm{mm}^{2}\right)$ was used, and this value is not exactly an optimal choice for the low-frequency inductors. It was chosen to allow a comparison of the results.

The auxiliary capacitor power loss (T2) has the same magnitude of the inductor losses, due to the high RMS current associated with its $\mathrm{R}_{\mathrm{se}}(0.5 \Omega$ considered in Table II).

For the semiconductors (except the input bridge) two different approaches were used. For the low-frequency circuits, the losses were estimated, assuming IGBT's are used as the power switches, considering the average current and voltage drop (3 V) and neglecting the switching losses.

For the HF topology, a typical $95 \%$ efficiency was used, as often reported in the literature, valid for the considered power range. Subtracting the other estimated losses, the difference was attributed to the transistor and output diode.

These semiconductor losses are about ten times higher in the HF circuit, obviously because of the switching losses.

\section{G. Heatsink}

In both the situations it was supposed to use TO-220 packages for $300 \mathrm{~W}$ applications (thermal resistance from junction to case $\mathrm{R}_{\theta \mathrm{\theta jc}}=2{ }^{\circ} \mathrm{C} / \mathrm{W}$ ) and TO-247 cases for the others $\left(\mathrm{R}_{\theta \mathrm{jc}}=0.7^{\circ} \mathrm{C} / \mathrm{W}\right)$.

The heatsink area was calculated considering the thermal resistance of a $1 \mathrm{~mm}$ thick, bright aluminium plate, in vertical position [9].

The bigger heatsinks necessary for the HF - boost have an important impact in the overall volume of this topology.

\section{H. EMI filter}

Due to the low-frequency commutation, topologies $\mathrm{T} 1$ and T2 practically do not need EMI input filters. On the other hand, the high-frequency boost PFC certainly calls for this additional circuitry.

As the design of such filter is not the objective of this paper, Table II indicates the volume of commercial EMI filters (50 $60 \mathrm{~dB}$ attenuation between $150 \mathrm{kHz}$ and $30 \mathrm{MHz}$ ). Note that the filter volume is much bigger than the inductor volume and that it is similar to the passive filter inductor size.

\section{Electronic circuitry}

The electronic circuit used by $\mathrm{T} 1$ and $\mathrm{T} 2$ is essentially a line synchronised gate signal generator. If an output voltage control is implemented, an additional feedback loop is necessary to adjust the pulse width.

For the HF - boost PFC, in CCM, commercial IC's are available, which normally require three input signals: the line voltage, the inductor current and the output voltage.

\section{EXPERIMENTAL RESULTS}

Figures 6 and 7 show the input current waveforms for topologies $\mathrm{T} 1$ and $\mathrm{T} 2$. In both cases the harmonic content is compliant with the standard limits.

\section{CONCLUSIONS}

A comprehensive comparison of high and low-frequency switched rectifier topologies allows the designer to select the right topology for a given application and power level.

Low-frequency switched rectifiers are a simple and cheap solution to achieve compliance with EMC regulations in AC/DC power supplies for household and general-purpose applications.

In comparison with totally passive circuits and highfrequency PFCs, including magnetic components, heatsinks, electronic circuitry and EMI filter, they present smaller overall volume.

The modified LF - boost PFC (topology T2), even using two inductors, minimises the converter volume. Its main drawback is the current stress on the switches and auxiliary

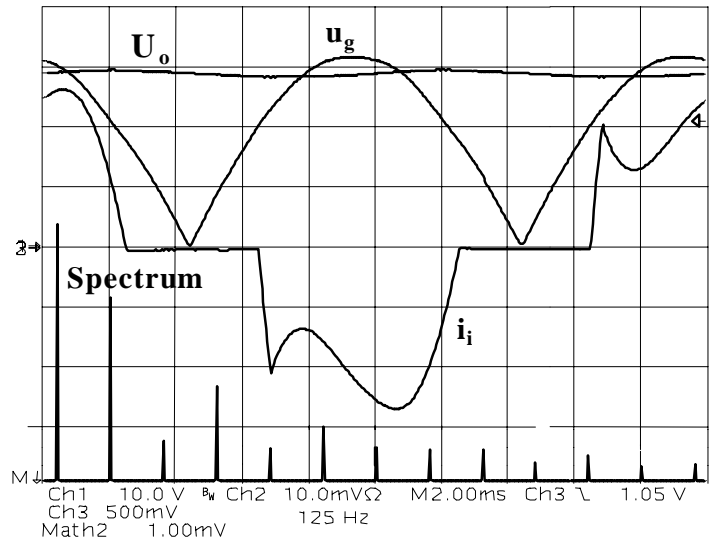

Fig. 6 - Rectified input voltage (100 V/div), input current ( $2 \mathrm{~A} / \mathrm{div})$ and its spectrum $\left(0.4 \mathrm{~A}_{\mathrm{rms}} / \mathrm{div}\right)$ at $\mathrm{U}_{\mathrm{i}}=230 \mathrm{~V}_{\mathrm{rms}}, \mathrm{U}_{\mathrm{o}}=284 \mathrm{~V}$ and $\mathrm{P}_{\mathrm{o}}=600 \mathrm{~W}$

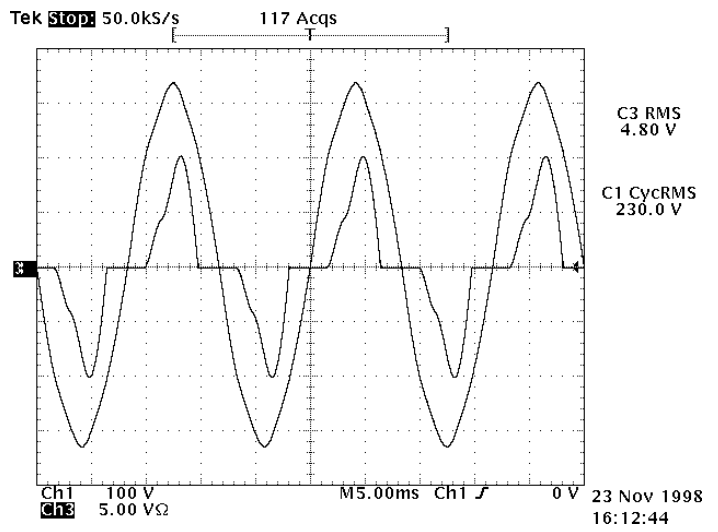

Fig. 7 - Input voltage $U_{\mathrm{i}}(100 \mathrm{~V} / \mathrm{div})$, input current $\mathrm{i}_{\mathrm{i}}(5 \mathrm{~A} / \mathrm{div})$ $\left(\mathrm{U}_{\mathrm{i}}=230 \mathrm{~V}_{\mathrm{rms}}, \mathrm{P}_{\mathrm{o}}=900 \mathrm{~W}\right)$

inductor and capacitor, resulting in a lower efficiency in 
comparison with topology T1.

In terms of total losses, the HF topology presents the worst results due to the switching losses. In spite of the reduced size of the inductor, the big heatsink and the EMI input filter may result in a lower power density than the active low-frequency circuits.

The main advantage of the HF - boost PFC is the voltage regulation that allows to compensate for load and line variations. The capability of the active LF circuits to provide such regulation is limited only to small load variations (about $50 \%)$.

\section{ACKNOWLEDGMENT}

The authors would like to thanks the Fundação de Amparo à Pesquisa do Estado de São Paulo (FAPESP) by Dr. Spiazzi and Dr. Buso fellowships during their stays in Brazil.

\section{REFERENCES}

[1] IEC 61000-3-2, International Electrotechnical Commission, 3, Genève, Switzerland, 1998.

[2] M. Jovanovic, D. E. Crow, "Merits and Limitations of Full-Bridge Rectifier with LC Filter in Meeting IEC 1000-3-2 Harmonic-Limit
Specifications," Proc. of the IEEE Applied Power Electronics Conf.. (APEC), March 1996, pp. 354-360.

[3] I. Suga, M. Kimata, Y. Ohnishi, R. Uchida. "New Switching Method for Single-Phase AC to DC Converter," Proc. of the Power Conversion Conference (PCC), 1993, pp.93-98.

[4] L. Rossetto, G.Spiazzi, P. Tenti, "Boost PFC with $100 \mathrm{~Hz}$ Switching Frequency Providing Output Voltage Stabilization and Compliance with EMC Standards", 1998 Proc. of the Industry Applications Society Annual Meeting, St. Louis, pp. 1567-1573.

[5] G. Spiazzi, S. Buso, "A Line-Frequency Commutated Rectifier Complying with IEC 1000-3-2 Standards," Proc. of the IEEE Applied Power Electronics Conf., March 1999.

[6] J. A. Pomilio, G. Spiazzi, "A Double-Line-Frequency Commutated Rectifier Complying with IEC 1000-3-2 Standards" Proc. of the IEEE Applied Power Electronics Conf., March 1999.

[7] J. A. Pomilio, G. Spiazzi, "A Low-Inductance Line-Frequency Commutated Rectifier Complying with IEC 1000-3-2 Standards," Proc. of the IEEE Power Electronics Specialists Conf. (PESC), June 1999.

[8] B. Mammano, L. Dixon: "Choose the Optimum Topology for High Power Factor Supplies", PCIM Magazine, March 1991, pp. 8-18.

[9] D. S. Steinberg: "Cooling Techniques for Electronic Equipment", John Wiley \& Sons, Inc., 1980. 